\title{
Effect of Total Quality Management Practices Factors on the Competitiveness: Evidence from Saudi Arabia
}

\author{
Faihan Mosaad Saud Al-Otaibi ${ }^{1}$, Mohammad Faleh Alharbi ${ }^{2}$ \& Abdullah Almeleehan ${ }^{3}$ \\ ${ }^{1}$ College of Business, University Utara University Malaysia, 06010 UUM, Kedah, Malaysia \\ ${ }^{2}$ College of Public Health and Health Informatics, Al-Qassim University, Saudi Arabia \\ ${ }^{3}$ College of Business, University of Hull, Yorkshair, HU67RX, United Kingdom \\ Correspondence: Faihan Mosaad Saud Al-Otaibi, College of Business, University Utara University Malaysia, \\ 06010, UUM, Kedah, Malaysia. E-mail: ft4s@hotmail.com
}

Received: February 22, 2015

Accepted: March 16, 2015

Online Published: April 20, 2015

doi:10.5539/ijbm.v10n5p85

URL: http://dx.doi.org/10.5539/ijbm.v10n5p85

\begin{abstract}
Total Quality Management Practices (TQMP) have been known to promote the performance of firms in terms of services, processes and products to meet customers' expectations. This paper examined the effect of TQMP factors on competitiveness of the construction firms in Saudi Arabia. The data for the study were gathered from managers of five major Saudi construction firms through interview schedules and questionnaires. Correlation and regression analysis were used to study the relationship between TQMP factors and competitiveness. The results of analysis indicated a significant positive relationship between the entire TQMP factors and competitiveness; specifically, between TQM practices and quality culture. The study indicated that construction firms in the country should address all major issues related to TQMP to remain competitive in the face of dynamic globalization, internal competition and threat of new entrants.
\end{abstract}

Keywords: total quality management practices, competitiveness, construction firms, Saudi Arabia

\section{Introduction}

Total Quality Management (TQM) practices have been known to promote the performance of firms in terms of services, processes and products to meet customers' expectations. Majority of senior management developed the most effective and suitable ways to apply such practices to boost and achieve industry successes. In the construction sector, TQM practices are capable of offering processes that brings consistency to the company performance and business process to achieve consumer satisfaction along with product and service quality. The implementation of TQM initiatives calls for extensive survey research on a periodic basis. The main aim is to provide customer feedback concerning the performance of the firm compared to its rivals from gauged via the attitudes of employees. The findings are expected to assist administrators in determining the performance of the firm according to the established criterion. The application of total quality management practices is a permanent process for the development of quality. The level of competitiveness of the company is confined to Porter's five forces namely, the threat of new entrants, bargaining power of the buyers, bargaining power of the suppliers, and the power of the firm compared to its rivals, and finally, the threat of alternatives (Vilanova et al., 2008).

A competitive firm is primarily referred to as one that has a greater market share, holds higher power than its buyers and suppliers, it forms barriers to new entrants and its products are non-substitutable. In other words, competitiveness refers to the capability of the firm to use its competitiveness in dynamic marketplace through products and services in order to attract and satisfy customers (Fujimoto et al., 2004). It is the ability of the firm to develop in the market in comparison to its rivals (Shi-Rong \& Guang-Kun, 2008).

Added to the above, competitiveness is a relative term that refers to the firm's capability of selling and providing goods and services at a specific marketplace. In this scenario, TQM practices lead to competitive advantage as shown by empirical research (Mellat-Parast \& Digman, 2008). According to Kumar et al. (1999), TQM frameworks such as Deming's 14 Prescriptive Points (1982), Crosby's 14 Steps (1979), an Juran's trilogy work enlighten companies to achieve competitive advantage and enable them to determine the onset of quality or development assessment. In the U.S. and Western Europe, TQM practices are widely acknowledged and such quality initiatives have also been applied in developing countries (Mohamed \& Yuan Jian, 2008). 
The term competitiveness is characterized by multiple facets that can be noted through different stages, which are country, industry, and company. The term stems from a Latin word 'competer' meaning taking part in trade competition in the market place. Competitiveness is invaluable in shedding light on the economic force of an entity according to the contenders in the global market economy of merchandise, services individuals, abilities and notions that surpasses geographical boundaries (Murtha \& Lenway, 1994).

At the company level, competitiveness is described as the capability of the firm to generate, design or market products with superior quality compared to its rivals (D'Cruz, 1992). In order to compete and obtain competitive edge, the major processes such as strategic management, human resource, operations management and technology management have to be taken into consideration. Firm level competitiveness has been well examined by specialists who evidenced that countries become competitors when their organizations are competitive. In relation to this, Christensen of the Harvard Business School, firms and not homelands, take part in competing in a global level (Porter, 1998). The entire competing companies have similar environmental factors as evidenced, with $36 \%$ of the firm's profitability variance based on their appearances and events (McGahan, 1999). In addition to this, Prahalad and Hamel (1990) focused on individual firms and strategies they use on a global scale and their resource positions that bring about the determination of their competitive sources.

This study will focus on the major factors of quality culture and competitiveness of the Saudi construction industry and demonstrates the impact of TQM practices implementation. The paper is organized in the following way - the next section (section 2) provides an overview of the related studies, followed by an outline of the methodologies and data collection in Section 3. Sections 4, 5 and 6 discuss the main findings, data analysis, study results and conclusion respectively.

\section{Literature Review}

\subsection{Development of TQM Practices}

The origin of TQM practices can be traced back from the early $19^{\text {th }}$ Century. Garvin was acknowledged for his work in tracing the history of U.S. quality movement on the basis of chronological focus changes over the years (Gonsalves, 2002). At the beginning of the $19^{\text {th }}$ century, he provided the four-stated TQM evolution as follows (Ohmer, 1997); the first era refers to the inspection era wherein quality inspection was made mandatory to ensure mass production reliability. This is followed by the quality control era in which major tools such as variability analysis, statistical sampling and statistical process control were launched. The Japanese employed some of the processes in the 1950s while the Americans were still oblivious to it. This era began at the beginning of the $20^{\text {th }}$ century. The third era is the quality assurance era where quality reached its peak-it developed from a limited manufacturing-based concept and was extended to cover the entire managerial field. The last era is the strategic quality management era describing the movement where in product and service quality were related to top management support, profitability, strategic planning, and quality-combined together to form an aggressive competitive advantage.

In fact, Japan's economic prominence among the countries around the world was attributed to TQM following the Second World War, and the U.S.'s restoration of competitiveness (Powell, 1995). As such, it can be argued that TQM is a force to be reckoned with in the present industrial economy. The origin of TQM can be traced back to Japan in the 1960s by Ishikawa, who employed quality management philosophies proposed by Deming and Juran in the 1950s and relayed it to other nations (Miyagawa \& Yoshida, 2005). Added to this, the pioneering TQM researchers can be traced back to 1949 when the Union of Japanese Scientists and Engineers (JUSE) established a committee of scholars, engineers, and government officials aimed towards enhancing Japanese productivity (Powell, 1995). Years after, statistical control and statistical training was created and Deming's philosophy was disseminated among Japanese manufacturers.

In the context of the U.S., TQM surfaced from the early mid-1990s owing to the high competition coming from Japanese companies (Hill, 2008). At that time, the situation was poor as businesses were showing ineffective performance and productivity and quality was slipping. As a result, TQM came about and was extensively acknowledged from 1946-1986 and studies from the pioneering authors like Deming, Juran, and Crosby changed American and Japanese business philosophies (James, 2008). Specifically, it boosted managerial innovations including quality circles, supplier firms, cellular industrial, just-in-time construction and the Hoshin development in Japan (Powell, 1995) whereas in the U.S., American companies including Ford, Xerox, and Motorola adopted TQM as proposed by Deming and other quality consultants. By the end of 1980s, several U.S. manufacturers had adopted TQM.

Nevertheless, no consensus has been reached as to TQM's inception although seven scholars were credited with its philosophies and principles and they are; Philip B. Crosby, W. Edwards Deming, Armand V. Feigenbaum, 
Kaoru Ishikawa, Joseph M. Juran, Walter A. Shewhart and Genichi Taguchi (Gonsalves, 2002; Hill, 2008). More specifically, among the above mentioned scholars, Deming and Jurand introduced the TQM in the U.S. after they came back from Japan. Deming played a significant role in the television serial entitled "If Japan Can, Why Can't We?" which remained on air in the 1980s. This encouraged the U.S. companies to employ practices of TQM. In the present time, several quality programs are being employed like Six Sigma, ISO9000, and Lean Sigma.

Aside from Deming, Crosby is another pioneering TQM researcher whose creation and promotion of the concept zero defects was attributed to rather than inspection and checking to guarantee quality (Ohmer, 1997). According to Crosby, quality management should be established as a permanent and enduring process supported by education. Contrastingly, Deming opined that the significance lies in the reduction of variability in manufacturing goods and in the costs. Deming stated that product requirements should be redefined to keep abreast with the dynamic customer requirements and demands. Another researcher is Feigenbaum (1991) who added to TQM literature by describing it as a philosophy of strategic commitment to excellence and emphasised employees' commitment to a performance that is free of error. Meanwhile, Juran proposed his trilogy of quality planning, quality control and quality improvement $(\mathrm{Hill}, 2008)$ and the Pareto principle, widely referred to as the $80: 20$ rule that posits that $80 \%$ of the problems stem from $20 \%$ of the reasons and therefore, it is important for managers to focus on the $20 \%$. Because of the increasing expectations for quality in global trade and in the expectations of customers, the development of quality declaration standards was established like the International Organization for Standardization (ISO) that was created in Geneva, Switzerland (James, 2008). In this regard, ISO9000 consists of different standards. Added to this, quality award models like the U.S. Malcolm Baldrige National quality Award (MBNQA), the European Quality Award, the Australian Quality Award and the Japanese Deming Prize launched prestigious levels and as a result, benchmarking became extensive in various firms (Al-Asiri, 2004). The awards reflect quality and its realization.

\subsection{TQM Practices in Construction Industry}

In the context of the construction industry, Hart (1994) described quality as taking three meanings ; getting the job done on a timely manner, ensuring that the fundamental features of the final initiative fall within the mandatory criteria, and lastly, receiving the job done within the boundary of the financial plan.

A quality construction project has to cover the above three dimensions and quality in construction is basically related with adherence to stipulations and appropriateness of use. In such industry, quality is referred to satisfying the requirements of the relevant individuals namely the designer, the constructor, the regulatory entities and the owner (Ferguson \& Clayton, 1988). The ISO 9000 certification in the construction industry brings about the development of the firm's reputation that is related to quality assurance in the engineering and construction project management (Bubshait \& Al-Atig, 1999). Moreover, most companies often make use of the ISO certification to market their services.

Dynamic competition in the national and international levels leads to greater quality levels in almost every business activities and industries. To ensure their competitive edge in the developing global market, construction firms in different countries attempt to reach acknowledged accepted quality levels based on TQM (ISO 9001 family quality certification) and quality award conditions. Nevertheless, there exist differences in the degree of TQM implementation in different countries. Literature in the field evidenced TQM's extensive acknowledgement as a practice via both frameworks (Wiele, 1998). TQM adopting companies include Morrison Construction Group (Sommerville, 1994), Takenaka Corporation (Jido, 1996), and Shui On Construction Co. (Fung \& Wong, 1995). Superior performance in terms of greater consumer satisfaction, higher project quality and market share have been reflected by several companies that adopted the practice (Wong \& Fung, 1999).

In the current times, TQM has been increasingly adopted by construction companies to assist in determining solutions to quality management as prior industries have aimed to and thus, it is logical that TQM may also be invaluable in the construction industry. Quality management primarily offers the firm with two competitive factors namely product quality and customer service (Gonsalves, 2002). Manufacturers in the international arena have been reported to effectively compete due to their great degree of process improvement in quality and customer-service aspects. On a similar line, quality management offers a competitive edge in the manufacturing as well as service industries.

However, the construction industry appears to be cautious in employing TQM practices as their short-term benefits are not significant and such an industry expect timely outcome (Love, Li, Irani, \& Holt, 2000). Adoption of TQM is a complicated process (Pheng \& Teo, 2004) as it is built on philosophy, principles, procedures and practices that are needed to satisfy customers and achieve productivity and business performance in the industry. 
The challenges in adopting TQM has also been reported by other studies like Motwani (2001) who contended that TQM implementation is riddled with monumental organizational transformation that requires the entire modification of its culture, process, strategic priorities and beliefs.

To this end, the alternative in the construction industry is re-engineering, a process that has been found to be effective for improvement more than business process re-engineering (BPR) and is superior to enhancements stemming from the implementation of TQM (Abdul-Hadi, Al-Sudairi, \& Alqahtani, 2005). This urged researchers to recommend the combination of TQM and BPR for a superior result. For instance, in the South African high-tech industry, the failed TQM adoption was reported to be isolated and fragmented (Winzker, 1999). It can thus be stated that in order to successfully compete in the global market, quality is not enough and quality method of a holistic nature that consists of extensive company spectrum and characteristics is recommended (Winzker, 1999).

In the context of Turkey, the evaluation of critical success factors in the construction industry showed that business management, fiscal situation, and features of owner-management are the top antecedents of success (Arslan \& Kivrak, 2008). The most critical factor is business management and it covers quality control. It is notable that in such a context, work quality and workmanship are not included in the first three factors. On the other hand, in the construction industry of Australia, the management of the industry is challenged by its highly fragmented and loose supply chains, and as such, TQM initiatives were not introduced until the government established a QA mandate for procuring projects (Love, Li, Irani, \& Holt, 2000).

Presently, it has been noted that construction firms are faced with the challenges of enhancing quality and satisfying customers via TQM implementation (Torbic \& Stroh, 1999). This is on top of the issues concerning lack of quality and the widespread corruption in the industry (Olken, 2004). Like other sectors, the construction sector defines quality by customers. In other words, quality is considered as an element judged from the viewpoint of the customer that meets their expectations and needs. Torbica (1997) is among the many studies that contributed to literature. He focused on the establishment of an effective and valid instrument that measures home buyer satisfaction and the understanding of the way TQM affects such satisfaction. Data was gathered from 16 medium to large residential companies in Florida and from home buyers of the firms concerning their satisfaction level. The findings showed that consumer consummation is the top critical aspect in achieving TQM and the study reported that service is the most significant determinant of home-buyer satisfaction.

In the current dynamic market environment, enhancing quality and customer satisfaction are the only ways to survive and thrive. Given the previous research results, it is interested to see the effects of TQM practices on the competiveness of construction industry in the context of Saudi Arabia.

\section{Methodology}

This study aims to examine the main factors that play a role in TQMP and accordingly, data was collected through personal interviews and questionnaires among the managers working in the five leading Saudi construction firms. Discussions were also held through email or on phone. Answers were then reviewed for consistency but no differences found.

The following section provides an overview of the theoretical framework with the aim of achieving the concerns of the effect of TQMP (top management, leadership, customer management, people management, supplier management, information quality management, process management, learning and continuous improvement) on the Saudi contractors competitiveness as mediated by quality culture.

\subsection{Conceptual Framework}

As mentioned in the previous section, organizations are recognizing the strategic significant of TQMP and hence, in the present study, the relationship between TQMP of construction firms, the quality culture and competitiveness in the market are considered.

A thorough review of literature reveals the effort made by the researcher to synthesize the quality management theory from the studies conducted (Anderson et al., 1994), including academic and management personnel in their quest to ensure quality. According to Anderson et al. (1994), the gist of the theory of Deming management method entails the development of an organizational system that boosts collaboration and learning to bring about the employment of management practices, which could result in permanent development in processes, goods and services, and employee satisfaction-these are significant in consumption of such services and products and in the firm's survival. This theory implies that the leadership of an organization has a key role in guaranteeing the quality management success (Anderson et al., 1994).

Deming management also encapsulates his fourteen points principle and in this regard, Anderson et al. (1994) 
stated that the success of the Deming administration style originates from hard work of management to maximize the knowledge and collaboration within the organization to allow the application of management and processes that reinforces and lengthens the life of the organization and customer satisfaction. The Deming procedure is employed to sustain worker achievement and developing services, goods and processes (Anderson et al., 1994).

The conceptual framework for this study is developed to relate TQM, quality culture and competitiveness, on the basis of the available literature, with TQMP considered as independent variable and competitiveness the dependent one. Added to this, quality culture is considered as a mediator in the relationship between the former two variables. TQMP includes eight factors-information and analysis (IA), customer focus (CF), education and training (ET) process management (PM), continuous improvement (CI), management supplier (MS), employee relation (ER) and top management commitment (TMC). The conceptual framework adopted for the study is given Figure 1.

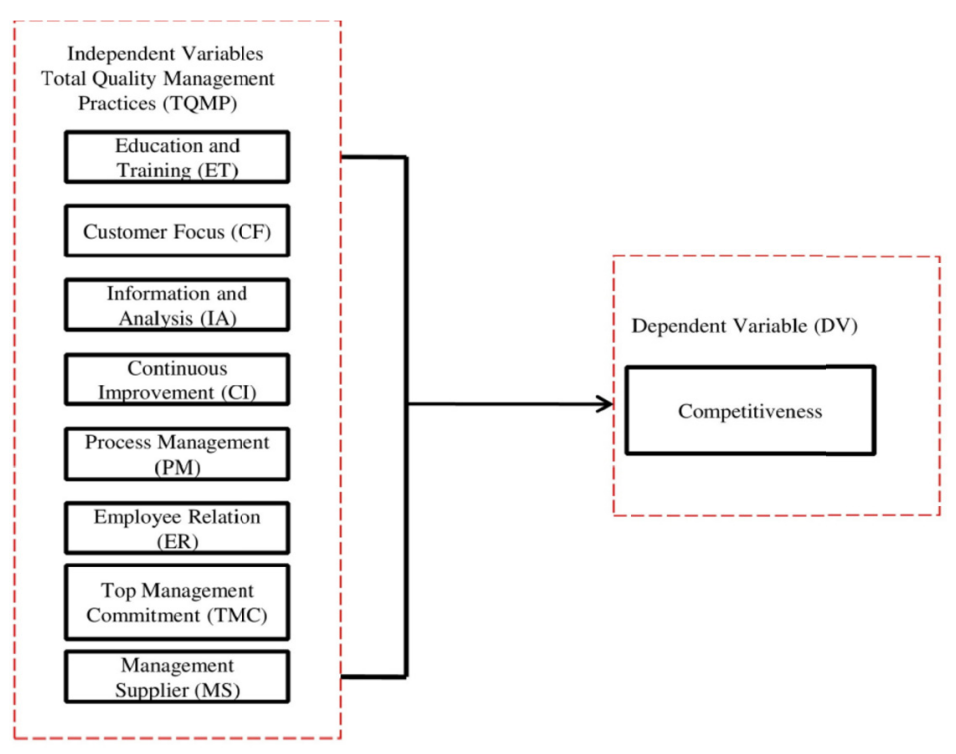

Figure 1. Conceptual framework

Source: Alotaibi et al. (2013).

\subsection{Relationship between TQMP and Competitiveness}

Although TQM is a concept that is acknowledged to be the most significant strategic source, its relationship with competitiveness remains under-researched. Among the few studies dedicated to TQM is Powell's (1995) examination of the concept and it being a potential source of competitive advantages. In a related study, Argus and Sagir (2001) revealed that TQM significantly impacts competitive advantage, which in turn, leads to a significant impact on financial performance of the firm. Meanwhile, Powell (1995) demonstrated that TQM practices indirectly impact the financial performance while being mediated by competitive advantage. Prior findings revealed that TQM-adopting firms achieved competitive advantages that are greater than their non-adopting counterparts (Brah et al., 2002; Powell, 1995). Hence, it can be stated that TQM on its own generally results in enhanced competitiveness and should not be combined with other strategies or processes.

\subsection{Data Collection Tools \& Techniques}

Before the survey questions were organized, it was pertinent to create clear and comprehensible instructions. Accordingly, a cover letter was attached to the questionnaire where in the instructions of filling in the questionnaires were elaborated. Specifically, it contained the research objective, the approximate time of completion, the questionnaire sections and their contents, an example of each question type, where the answers are gauged through a Likert scale.

The questionnaire was divided into four sections; demographic questions, TQMP questions, competitiveness questions, and questions pertaining to quality culture. Questionnaire structuring enables respondents to complete the questionnaire without issues. In this case, the organization of the questionnaire into four parts was conducted 
to steer clear of ambiguity as suggested by Neuman (2006). Table 1 provides the measurement of the variables in different sections. Section -1 contained six questions pertaining to demographic information and general information of the respondents. Section 2 consists of forty-three questions examining the impact of TQMP on the competitiveness of the contracting firm. Section 3 contained 35 questions related to competitiveness and section 4 contained thirty-five questions, among which 11 pertained to the external environment of the contractor, and 24 examined the contracting firm in terms of organizational resources and capabilities in order to gauge competitiveness.

The entire questions in the questionnaire were close-ended and gauged with the help of a five-point Likert scale except that of demographic questions. The scales ranged from 1 depicting strongly disagree to 5 depicting strongly agree.

Table 1. Measurement of variables

\begin{tabular}{|c|c|c|c|}
\hline \multirow{2}{*}{$\begin{array}{l}\text { Factor categories } \\
\text { Demographic }\end{array}$} & \multirow{2}{*}{$\begin{array}{l}\text { Main variables } \\
\text { Background information, company profile }\end{array}$} & \multicolumn{2}{|c|}{ No. of items Total } \\
\hline & & 6 & 6 \\
\hline \multirow[t]{12}{*}{ Total quality management practices } & Education \& Training (ET) & 4 & 43 \\
\hline & Customer Focus (CF) & 6 & \\
\hline & Information \& Analysis (IA) & 6 & \\
\hline & Continuous Improvement (CI) & 3 & \\
\hline & Process Management (PM) & 6 & \\
\hline & Employee Relation (ER) & 8 & \\
\hline & Top Management Commitment (TMC) & 6 & \\
\hline & Management Supplier (MS) & 4 & \\
\hline & Teamwork Orientation (TO) & 5 & \\
\hline & Mission \& Goals Orientation (MGO) & 5 & \\
\hline & Management Style (MST) & 6 & \\
\hline & Personal Influence $\backslash$ Performance (PIP) & 6 & \\
\hline \multirow[t]{9}{*}{ Competitiveness } & Description (D) & 5 & 35 \\
\hline & Task Environment (TE) & 6 & \\
\hline & Corporate Image (CIM) & 3 & \\
\hline & Technology and Innovation (TI) & 4 & \\
\hline & Marketing and Capability (MC) & 4 & \\
\hline & Financial and Capability (FC) & 4 & \\
\hline & Project Management Skill (PMS) & 5 & \\
\hline & Organization and Human Resource (OHR) & 4 & \\
\hline & Total & & 84 \\
\hline
\end{tabular}

\subsection{Reliability Analysis}

The reliability test is used to measure the error-free or bias-free element of the measurement (Sekaran, 2003). Accordingly, Cronbach's alpha was obtained to determine the scale's reliability where, cronbach alpha coefficient over 0.70 was considered acceptable (Nunnally \& Bernstein, 1994; Sekaran, 2006). In other words, the acceptable cut-off level of 0.70 was adopted. In addition, the corrected item-total correlation for the entire factors was 0.30 as suggested by prior studies (e.g., Henryson, 1971; Tatham et al., 2006; Palant, 2004). Suggestions from the prior studies were employed in this study to assess the reliability and internal consistency of the scale. Table 2 presents the results of the analysis. 
Table 2. Reliability analysis of total quality management practices

\begin{tabular}{lllllll}
\hline Variable & Factors & $\begin{array}{l}\text { No. of the items } \\
\text { before reliability }\end{array}$ & $\begin{array}{l}\text { No. of the items } \\
\text { after reliability }\end{array}$ & $\begin{array}{l}\text { Alpha before the } \\
\text { reliability }\end{array}$ & $\begin{array}{l}\text { Alpha } \\
\text { reliability }\end{array}$ & $\begin{array}{l}\text { after } \\
\text { Overall } \\
\text { reliability }\end{array}$ \\
\hline Total quality & ET & 4 & 4 & 0.930 & 0.930 & 0.855 \\
Management Practices & CF & 6 & 4 & 0.566 & 0.851 & \\
& IA & 6 & 4 & 0.637 & 0.854 \\
& CI & 3 & 3 & 0.806 & 0.806 \\
\\
PM & 6 & 4 & 0.591 & 0.831 \\
& ER & 8 & 7 & 0.669 & 0.759 \\
& TMC & 6 & 4 & 0.388 & 0.951 \\
\\
MS & 4 & 4 & 0.953 & 0.953 \\
\hline
\end{tabular}

\subsubsection{Total Quality Management Practices (TQMP)}

The reliability test was employed on all eight factors of TQMP. The reliability scores of the factors are presented in Table 2. Specifically, the results included ET, CI and MS, where PM5, PM6, IA5, CF5, CF6, TM6, and TMC5 were dropped owing to unreliability.

\subsubsection{Competitiveness}

Competitiveness in this study consisted of eight elements namely description (D), corporate image (CIM), technology and innovation (TI), task environment (TE), financial capability (FC), marketing capability (MC), organization and human resource (OHR), and project management skill (PMS). According to the results, the entire elements of description, task environment, technology and innovation, corporate image, financial capability and marketing capability were included with the exception of PMS5, and OHR4 owing to their unreliability. The result is shown in Table 3 .

Table 3. Reliability analysis of competitiveness

\begin{tabular}{ccccccc}
\hline Variable & Factors & $\begin{array}{l}\text { No. of the items } \\
\text { before reliability }\end{array}$ & $\begin{array}{l}\text { No. of the items } \\
\text { after reliability }\end{array}$ & $\begin{array}{l}\text { Alpha before the } \\
\text { reliability }\end{array}$ & $\begin{array}{l}\text { Alpha } \\
\text { reliability }\end{array}$ & $\begin{array}{l}\text { after } \\
\text { Overall } \\
\text { reliability }\end{array}$ \\
\hline Competitiveness & D & 5 & 5 & 0.912 & 0.912 & 0.806 \\
& TE & 6 & 6 & 0.848 & 0.848 \\
& CIM & 3 & 3 & 0.909 & 0.909 \\
TI & 4 & 4 & 0.827 & 0.827 \\
MC & 4 & 4 & 0.874 & 0.874 \\
FC & 4 & 4 & 0.960 & 0.960 \\
PMS & 5 & 4 & 0.664 & 0.898 \\
OHR & 4 & 3 & 0.632 & 0.860 \\
\hline
\end{tabular}

According to the results, a project do not have a possibility of failing because of merely one or more hidden factors as all diverse issues and factors are interrelated. The findings determined factors that contribute to successful implementation in TQM in Saudi construction industry (See Table 4).

Literature provides untested and unstructured findings that TQM is widely known to be the most popular business strategy which firms are currently adopting, particularly in developing countries. The Saudi construction industry is no different, specifically in the five major construction companies. It is however notable that these firms have not realized the full advantages of TQM although there are signs of successes and enhanced competitiveness. 
Table 4. Implementation of TQM by location

\begin{tabular}{lll}
\hline Location & Frequency & Percentage \\
\hline Riyadh & 202 & $52.1 \%$ \\
Aljouf & 7 & $1.8 \%$ \\
Najran & 38 & $9.8 \%$ \\
Eastern Province & 66 & $17 \%$ \\
Mecca & 75 & 19.3 \\
\hline
\end{tabular}

In order to examine the adopted measures efficiency and effectiveness, both reliability and exploratory factor analysis were conducted prior to the main variables analysis. The results are discussed in detail in the following section.

\section{The Results}

\subsection{Reliability Test}

The measurement of scales has a minimum reliability of 0.60 as suggested by Pallant (2010). Such reliability shows the level to which consistency exists among the different variable measures (Sekaran \& Bougie, 2006). It measures the consistency level of a specific phase of decisions and behaviour. Cronbach's alpha is frequently used to indicate internal consistency and reliability (Sekaran, 2003) and all authors are of the consensus that the acceptable value of Cronbach's alpha is 0.70 and higher (Sekaran \& Bougie, 2006).

The elements reliability analyses are presented in Table 5. The values of Cronbach's alpha for the entire dimensions exceed 0.70 indicating that all the measures have significant reliability.

Table 5. Reliability results

\begin{tabular}{|c|c|c|c|}
\hline \multirow[b]{2}{*}{ Constructs } & \multirow{3}{*}{$\begin{array}{l}\text { Variables } \\
\text { Education \& training }\end{array}$} & \multicolumn{2}{|c|}{$\alpha$} \\
\hline & & No. of items & Cronbach's alpha \\
\hline \multirow{8}{*}{$\begin{array}{l}\text { Total quality management } \\
\text { practices }\end{array}$} & & 4 & 0.899 \\
\hline & Customers focus & 4 & 0.930 \\
\hline & Information $\&$ analysis & 4 & 0.817 \\
\hline & Continuous \& improvement & 3 & 0.766 \\
\hline & Process management & 4 & 0.887 \\
\hline & Employee relations & 7 & 0.929 \\
\hline & Top management commitment & 4 & 0.884 \\
\hline & Management of supplier & 4 & 0.803 \\
\hline \multirow[t]{6}{*}{ Competitiveness } & Task environment & 5 & 0.840 \\
\hline & Corporate image & 6 & 0.933 \\
\hline & Technology \& innovation & 3 & 0.862 \\
\hline & Marketing capability & 4 & 0.889 \\
\hline & Financial capability & 4 & 0.876 \\
\hline & Project management skill & 4 & 0.720 \\
\hline
\end{tabular}

\subsection{Correlation Analysis}

The correlation test is a statistical analysis used to shed light on the force and trend of linear relationship between two variables (Pallant, 2001). It is the level to which the correlation is utilized to identify the significance and strength of the variables relationship. In this study, the Pearson correlation coefficient ( $r$ ) was used for the evaluation of such correlation. According to Cohen (2013), correlation analysis describes the intensity and extent of two variables correlation. Tables 6 and 7 present the summary of the correlations between this study's variables. 
Table 6. Cohen's principle of correlation strength

\begin{tabular}{ll}
\hline$R$ & Strength of relationship \\
\hline 0.10 to 0.29 & Low \\
0.30 to 0.49 & Moderate \\
0.50 to 1.0 & High \\
\hline
\end{tabular}

Table 7. Summary of correlations of variables

\begin{tabular}{lll}
\hline Study variables & Correlation coefficient & Strength of relationship \\
\hline TQMP and Competitiveness & $0.412^{* *}$ & Moderate \\
\hline
\end{tabular}

Note. ${ }^{* *} \mathrm{p}<0.01$.

\subsection{Regression Analysis}

The relationship between TQMP factors and competitiveness were obtained with the help of the multiple regression analysis but prior to the hypotheses testing, some assumptions had to be confirmed and these include linearity, normality, homoscedasticity, and independence of error terms, multivariate outliers and multicollinearity (Coakes \& Steed, 2003; Sekaran \& Bougie, 2006; Sekaran, 2006; Pallant, 2001).

Therefore, the entire factors were investigated for skewness and kurtosis. Tatham et al. (2006) stated that skewness and kurtosis levels should fall between -2.00 and +2.00 at the significance level of 0.05 . None of the factors had skewness and kurtosis over 2.0 indicating that information was distributed normally. This examination at the univariate level was carried out before the affirmation of multivariate normality (Table.8).

Table 8. Statistic values of skewness and kurtosis (descriptive statistics)

\begin{tabular}{lllll}
\hline & \multicolumn{3}{c}{ Skewness } & \multicolumn{1}{c}{ Kurtosis } \\
\hline Variables & Statistic & Std. Error & Statistic & Std. Error \\
\hline $\begin{array}{l}\text { Total quality } \\
\text { management practices }\end{array}$ & 0.286 & 0.124 & 0.167 & 0.247 \\
\begin{tabular}{l} 
Competitiveness \\
\hline
\end{tabular} & -0.052 & 0.124 & -0.246 & 0.247 \\
\hline
\end{tabular}

\subsection{Independence of Error Term}

The Durbin-Watson statistics are often utilized to evaluate the effectiveness of independence of error assumptions. On the basis of Coakes and Steed's (2003) study, the values of freedom from error term should fall between Durbin-Watson of 1:50-2:50. The results presented in Table 9, show that the values satisfy such assumption and that auto-correlation issues are non-existent.

Table 9. Durbin-Watson statistical value

\begin{tabular}{llllccc}
\hline Model & IV & DV R square & Adjusted & R square & Std. error of the estimate & Durbin-watson \\
\hline 1 & TQMP & Competitiveness & 0.170 & 0.168 & 0.33484 & 1.507 \\
2 & TQMP & Quality culture & 0.580 & 0.579 & 0.29397 & 1.782 \\
3 & Quality culture & Competitiveness & 0.125 & 0.122 & 0.34384 \\
\hline
\end{tabular}

\subsection{Multicollinearity Test (Independence of Independent Variables)}

Added to the explained assumptions, multicollinearity is another assumption that is significant and its absence should be ensured. The processes of collinearity were conducted to assess issues of multicollinearty of predictors. For this process, the Tolerance Value and Variance Inflation Factor (VIF) were obtained. In this regard, Sekaran and Bougie (2006) stated that tolerance values fall between 0 to -1 , with 1 being the non-relation of a variable to other variables while 0 being the variable's perfect correlation with another. Added to this, the standard cut off value of VIF is 10 with all the predictors required to obtain values that are less than 10 . In this study, the values obtained after the multicollinearity test are displayed in Table 10.

It is evident from the table (Table 10) that multicollinearity was non-existent between independent variables as 
the tolerance values were less than 1.00 and the VIF values were less than 10 . Therefore, the resulting data can now be examined through relevant regression analysis as the assumptions have been amply met.

Table 10. Tolerance value and variance inflation factor (VIF) test

\begin{tabular}{lccc}
\hline \multicolumn{2}{l}{ Colinearity statistics } & & \\
\hline IV & DV & Tolerance & VIF \\
\hline TQMP factors & Competitiveness & 0.73 & 1.37 \\
\hline
\end{tabular}

\section{Discussion}

\subsection{Relationship between TQMP Factors and Competitiveness}

This study examines the relationship between TQMP factors including education and training, customer focus, continuous improvement, process management, information and analysis, top management commitment, employee relations and management of supplier, on the competitiveness of Saudi contractors. The researchers made use of the Pearson correlation analysis to investigate the above relationship and Table 11 lists the results obtained.

\subsection{TQMP Factors Affecting Competitiveness}

This research was focused on examining the effect of TQMP factors (i.e. education and training, customer focus, continuous improvement, process management, information and analysis, top management commitment, employee relations and management of supplier) on the Saudi contractors' competitiveness.

Table 11. Correlation between TQMP Factors and competitiveness $(n=388)$

\begin{tabular}{ll}
\hline Factors & Competitiveness \\
\hline Education \& training & $0.129^{* *}$ \\
Customer focus & $0.127^{* *}$ \\
Information and analysis & $0.168^{* *}$ \\
Continuous improvement & $0.154^{* *}$ \\
Process management & $0.176^{* *}$ \\
Employee relations & $0.567^{* *}$ \\
Top management commitment & $0.133^{* *}$ \\
Management of supplier & $0.168^{* *}$ \\
\hline
\end{tabular}

Note. $* * \mathrm{p}<0.01$.

The research hypotheses were examined via linear regression analysis to determine the manner in which the contingency variables predict a specific result in terms of quality culture and competitiveness. In this regard, the normal value of $R^{2}$ was considered as 1 , indicating ideal linear correlation between the variables. Conversely, an $R^{2}$ value of 0 indicates the absence of relationship. Added to this standard multiple regression analysis is related to a modified $R^{2}$ value. According to Pallant (2001), the adjusted ...statistic 'corrects' the value of $R^{2}$ to enhance the estimation of the value of population. In this study, the adjusted $R^{2}$ statistic factors constituted a significant percentage of variance in the competitiveness of contractors $\left(R^{2}=0.366, F=27.346, p<0.001\right)$ indicating that TQMP factors (i.e. education and training, customer focus, continuous improvement, process management, information and analysis, top management commitment, employee relations, and management of supplier) explained $36.6 \%$ of the overall variance in competitiveness. Detailed results are presented in Table 12. 
Table 12. Multiple linear regression analysis among total quality management practices (TQMP) elements as IVs and competitiveness as DV

\begin{tabular}{llllll}
\hline Model summary Model 1 & $\mathrm{R}$ & $\mathrm{R}^{2}$ & Adjusted $\mathrm{R}^{2}$ & Std. Error of the estimate & \\
\hline ANOVA (b) & $0.605(\mathrm{a})$ & 0.366 & 0.353 & 0.2953 & $\mathrm{p}$ \\
Model 1 & Sum of squares & $\mathrm{df}$ & Mean square & $\mathrm{F}$ & 0.000 \\
& 19.081 & 8 & 2.385 & 27.346 & \\
& 33.055 & 379 & 0.087 & & \\
& 52,136 & 387 & & & $\mathrm{p}$ \\
& & & & & $0.000^{* * *}$ \\
\hline Coefficients (a) Model 1 & Unstandardized & & & $\mathrm{S} . \mathrm{zed}$ & 0.576 \\
& $\mathrm{~B}$ & Std. Error & Beta & $\mathrm{t}$ & $0.033^{*}$ \\
(Constant) & 2.438 & 0.164 & & 14.907 & 0.753 \\
Education \& training & -0.008 & 0.014 & -0.024 & -0.560 & 0.099 \\
Customers focus & -0.051 & 0.024 & -0.105 & -2.146 & $0.013^{*}$ \\
Information \& analysis & 0.009 & 0.028 & 0.015 & 0.315 & $0.000^{* * *}$ \\
Continuous improvement & 0.040 & 0.024 & 0.076 & 1.653 & 0.901 \\
Process management & 0.039 & 0.015 & 0.106 & 2.503 & $0.000^{* * *}$ \\
Employee relations & 0.235 & 0.019 & 0.562 & 12.369 &
\end{tabular}

It is evident from the above table (Table 12), the results obtained showed that some TQMP factors namely customer focus, process management, management of supplier and employee relations significantly impacted the competitiveness of Saudi construction firms, while others including information and analysis, education and training, top management commitment, continuous improvement did not have any significant impact on the same.

\section{Conclusion}

The effectiveness of TQMP resulting in sustainable competitive advantage and improved performance has long been focused. This study examined the role of TQMP factors on competiveness of Saudi construction firms. It examined the role of quality culture as a mediator in the TQMP- competitiveness relationship. This study used correlation and regression analysis to examine the relationship among TQMP factors and competitiveness.

The findings showed that TQMP factors explained $36.6 \%$ of the variance in competitiveness, and $68.1 \%$ of the variance in quality culture. On the other hand, quality culture explained $12.5 \%$ of the competitiveness variance, where the former was found to partially mediate the TQMP-competitiveness relationship.

From the review and the study findings it could be inferred that Saudi construction industry despite being one of the largest in the world, is riddled by issues that need to be addressed if it is to remain competitive in the face of dynamic globalization, internal competition and threat of new entrants. This issue is important as the buyers' bargaining power is unreasonably high owing to the sector's low barriers of entry and the standard service provided by all construction firms.

\section{References}

Agus, A., \& Sagir, R. M. (2001). The structural relationships between total quality management, competitive advantage and bottom line financial performance: An empirical study of Malaysian manufacturing companies. Total Quality Management, 12(7-8), 1018-1024. http://dx.doi.org/10.1080/09544120100000029

Al-Hammad, A. (1993). Factors affecting the relationship between contractors and their sub-contractors in Saudi Arabia. Building Research Information, 21, 269-273. http://dx.doi.org/10.1080/09613219308727315

Al-Kharashi, A., \& Skitmore, M. (2009). Causes of delays in Saudi Arabian public sector construction projects. Construction Management Economics, 27, 3-23. http://dx.doi.org/10.1080/01446190802541457

Alotaibi, F., Yusoff, R. Z., \& Islam, R. (2013). Assessing the impact of total quality management practices and quality culture with competitiveness of Saudi contractors. American Journal of Applied Sciences, 10, 638-645. http://dx.doi.org/10.3844/ajassp.2013.638.645

Anderson, J. C., Rungtusanatham, M., \& Schroeder, R. G. (1994). A theory of quality management underlying 
the Deming management method. Academic Management Review, 9, 472-509. http://dx.doi.org/10.5465/AMR.1994.9412271808

Brah, S. A., Serene T. S. L., \& Rao, B. M. (2002). Relationship between TQM and performance of Singapore companies. International Journal of Quality \& Reliability Management, 19, 356-379. http://dx.doi.org 10.1108/02656710210421553

Coakes, S. J., \& Steed, L. G. (2003). SPSS Analysis without Anguish: Version 11.0 for Windows (1st ed.). John Wiley and Sons Australia, Milton Qld, Australia.

Cohen, J. (2013). Statistical power analysis for the Behavioral Sciences (1st ed.). Routledge.

D'Cruz, J. R. (1992). New compacts for Canadian competitiveness (1st ed.). DIANE Publishing, Toronto, Kodak Canada.

Fujimoto, J. G., Wojtkowski, M., Srinivasan, V. J., Ko, T. H., \& Duker, J. S. (2004). Ultrahigh-resolution, high-speed, Fourier domain optical coherence tomography and methods for dispersion compensation. Optics Express, 12, 2404-2422. http://dx.doi.org/10.1364/OPEX.12.002404

Sekaran, U., \& Bougie, R. (2006). Research methods for business: A skill building approach (5th ed.). John Wiley and Sons, Chichester.

Sekaran, U. (2006). Research Methods for Business: A Skill Building Approach (1st ed.). Wiley India Pvt.

Sekaran, U. (2003). Research methods for business students (1st ed.). Pearson Education India, Delhi.

Shi-Rong, L., \& Guang-Kun, C. (2008). Evaluation on competitiveness of construction projects from the perspective of construction main bodies. Proceedings of the 4th International Conference on Wireless Communications, Networking and Mobile Computing, Oct. 12-14, IEEE Xplore Press, Dalian. http://dx.doi.org/10.1109/WiCom.2008.1839

Stewart, R. A. (2007). IT enhanced project information management in construction: Pathways to improved performance and strategic competitiveness. Automation in Construction, 16, 511-517. http://dx.doi.org10.1016/j.autcon.2006.09.001

Tatham, R. L., Anderson, R. E., \& Black, B. (2006). Multivariate data analysis (5th ed.). Academic Internet Publication, Moorpark, CA.

Henryson, S. (1971). Analysis and Using Data on Test Items. In Thorndike, R. L., \& W. H. Angoff (Eds.), Educational Measurement. American Council on Education, Washington.

Kumar, A., Motwani, J., Douglas, C., \& Das, N. (1999). A quality competitiveness index for benchmarking. Benchmarking an International Journal, 6(1), 12-21. http://dx.doi.org/10.1108/14635779910258139

McGahan, A. M. (1999). Competition, strategy and business performance. California Manage. Rev., 41, 74-101. http://dx.doi.org/10.2307/41165998

Mellat-Parast, M., \&. Digman, L. A. (2008). Learning: The interface of quality management and strategic

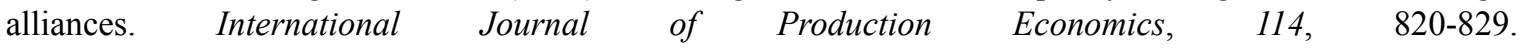
http://dx.doi.org/10.1016/j.ijpe.2008.04.003

Mohamed, S. S. (2008). The impact of the organizational culture on the implementation of TQM programs (pp. 386-389). Proceedings of the International Colloquium on Computing, Communication, Control and Management, Guangzhou: IEEE Xplore Press. http://dx.doi.org/10.1109/CCCM.2008.303

Murtha, T. P., \& Lenway, S. A. (1994). Country capabilities and the strategic state: How national political institutions affect multinational corporations' strategies. Strategic Managenet Journal, 15, 113-129. http://dx.doi.org /10.1002/smj.4250151008

Neuman, W. L. (2006). Social research methods: Qualitative and quantitative approaches (6th ed.). Pearson, Boston.

Nunnally, J. C., \& Bernstein, I. H. (1994). Psychometric Theory (3rd ed.). McGraw-Hill.

O’Brien, M. J., \& Al-Biqami, N. M. (1999). Survey of information technology and the structure of the Saudi Arabian construction industry. Proceedings of the 8th International Conference on Durability of Building Materials and Components, Information Technology in Construction, CIB W78 Workshop, (TCW' 99), Ottawa, Canada.

Palant, J. (2004). SPSS Survival Manual (2nd ed.). Berkshire: Open University Press. 
Pallant, J. (2001). SPSS Survival Manual: A step by step Guide to Data Analysis Using SPSS for Windows (1st ed.). Buckingham, Open University Press.

Pallant, J. (2010). SPSS Survival Manual: A Step by Step Guide to Data Analysis Using SPSS. Buckingham: Open University Press.

Porter, M. E. (1998). Clusters and the new economics of competition. Harvard Business Review, 76, 77-90.

Powell, T. C. (1995). Total quality management as competitive advantage: A review and empirical study. Strategic Management Journal, 16, 15-37. http://dx.doi.org/10.1002/smj.4250160105

Prahalad, C. K., \& Hamel, G. (1990). The core competence of the corporation. Harvard Business Review, 68, 79-87.

Vilanova, M., Lozano, J. M., \& Arenas, D. (2008). Exploring the nature of the relationship between CSR and competitiveness. Journal of Business Ethics, 87, 57-69. http://dx.doi.org/10.1007/s10551-008-9812-2

Zikmund, W. G., Babin, B., Carr, J., \& Griffin, M. (2003). Business Research Methods (9th ed.). Cengage Learning.

\section{Copyrights}

Copyright for this article is retained by the author(s), with first publication rights granted to the journal.

This is an open-access article distributed under the terms and conditions of the Creative Commons Attribution license (http://creativecommons.org/licenses/by/3.0/). 